\title{
Inclusive Gamified Participation: Who are we inviting and who becomes engaged?
}

\author{
Sarah-Kristin Thiel \\ Michaela Reisinger \& Kathrin Röderer \\ Matthias Baldauf \\ Department for Computer Science \\ Center for Technology Experience \\ Information and Process Management \\ Aarhus Universitet \\ thiel@cs.au.dk \\ Austrian Institute of Technology \\ FHS St.Gallen \\ firstname.lastname@ait.ac.at \\ matthias.baldauf@fhsg.ch
}

\begin{abstract}
Recent evaluations have shown that up until now, e-participation platforms have not been very effective in involving citizens in public decision-making. This is partly due to these novel forms of engagement not seeming to reach citizens beyond the "usual suspects" of public participation. A trending approach to make these platforms more attractive, especially for less involved social groups, is to incorporate game-like elements. This research investigates the influence of demographical variables on participation and motivation when using a mobile gamified participation application. Our results show that participation was affected by age. The data further suggests that youth is both interested in urban planning and welcomes mobile participation forms, whereas older individuals feel less invited by novel technologies and engage less. Yet, older individuals and those less enthusiastic about games were not entirely put off by the included game elements.
\end{abstract}

\section{Introduction}

Ever decreasing voter turnouts are just one of the signs indicating that traditional forms of participation are no longer reaching the broad population [1, 2]. However, there is a growing body of people engaging in debates through non-official means such as social media (e.g. Twitter, Facebook) showing that they care about current issues. Instances such as Stuttgart 21 (a divisive railway project in Germany) or reactions to "Brexit" on Twitter indicate that participation is changing.

Citizens nowadays prefer more direct forms of participation to voice concerns and ideas [3]. With the objective to direct this activism into official channels, scholars and governmental officials have started to make use of contemporary information and communication technologies (ICTs) such as smartphones as participation channels (cf. [4]).

While this resulted in a wide range of services that allow people to express their opinion, the overall level of involvement still remains rather low. Recent efforts to utilize contemporary ICTs (e-participation) have not yet been very effective [5], particularly not in encouraging the previously non-engaged $[6,7]$. In fact, evaluations have shown that e-participation mainly engages the "usual suspects" of participation (e.g. those intrinsically motivated, highly educated), reinforcing the "civic engagement gap" [8]. Aiming for more inclusive participation, it is necessary to explore how other (social) groups can be encouraged to engage in public decision-making and to discuss participation barriers, e.g. for those less familiar with technologies [9], particularly elderly citizens. The so-called digital and generational divide [10] risks the marginalization of disadvantaged service users [11]. While the digital divide and its implications seem to be acknowledged $[12,13]$, there is yet little work on how different social groups interact with mobile participation platforms $[14,15]$. This paper therefore explores demographic differences in an e-participation process regarding pre-conditions, participation behavior and implications.

A recent approach to attract those previously less or non-engaged is to incorporate elements and concepts characteristic to games into participation platforms [16, 17]. The gamification approach [18] has been shown to influence the motivations of users and thus increase engagement $[19,20,21]$. Yet, gamification remains a highly controversial matter: Not everyone is affine to games or reacts positive to gamification, particularly in the field of public participation, which is denoted to be too serious to afford games [22]. Accordingly, some user groups might be alienated by its use and stop [23]. Existing literature suggests differences for age and gender in gamified applications [24], yet, the differences of perceived benefits for social groups have received only little attention so far [25].

Hoping to shed light on who feels invited (i.e. encouraged) by a gamified participation application, we investigated whether demographic differences exist in a) pre-conditions for public participation (e.g. attitudes, beliefs), b) actual usage patterns, c) factors encouraging 
the use of participation platforms and d) implications of engagement using a mobile gamified participation application in a long-term field trial in Turku (Finland).

\section{Background}

In the following, we survey prior work in relevant fields, namely e-participation, gamification, and their intersection gamified participation.

\section{1. e-Participation}

Political participation has been shown to be dominated by people with higher income and advanced education [26]. This also applies to e-participation: Those with higher income tend to have greater social networks as well as more resources (i.e. devices and skills) available for participation [27].

One branch of e-participation research investigates whether employing technologies introduces new barriers to participation and by doing so creates or enforces the digital [28] or generational divide [10], where older individuals are presumed to struggle with operating novel technologies [29]. The latter is especially worrisome considering that older and higher educated citizens tend to be more active in traditional forms of participation (e.g. town hall meetings, voting) [30]. Lack of appropriate interaction forms for this group might thus exclude them from novel participation processes. Yet, their (traditional) engagement could also be associated with being less limited by opening hours. When creating forms of participation that do not entail spatial and temporal barriers, younger individuals might have better chances to engage. This argument is supported by online discussion forums having a broader demographic basis (elderly \& young) than more traditional engagement forms [30], indicating that technology might have the potential to attract less engaged groups without alienating the traditionally engaged.

It is a common proposition that young people are either not interested in politics or do not engage in discussions regarding public affairs.According to data from official participation channels, youth is rather inactive in traditional participation [31], and is even said to be disconnected from public life [32]. In reality, young people are quite active in other areas: For example, young people are as likely to sign e-mail petitions as their older counterparts. Moreover, they are very active in volunteering [31]. Numerous tweets and Facebook posts accompanying recent political issues reflect youth's high levels of involvement through alternative or novel forms [10]. It does not seem to be disinterest that is keeping this age group from participating (cf. [33]). Reasons for their non-participation are more likely to be found in their feeling that nobody is listening [to them] [34]. In fact, they receive fewer invitations to participate than their elders [31]. Accordingly, youth's non-participation is fueled by alienation from, and cynicism about politics, which could be interpreted as a result of exclusion and disenfranchisement [35].

The adoption of e-participation is very much influenced by factors mediating the general adoption of technology. Even among young users of similar education who are usually understood to be highly connected and proficient with information technology, gender, socio-economic background, and ethnicity are related to computer and Internet proficiency as well as diversity of use [36]. A divide by age, gender and socio-economic status is seen not only in Internet self-efficacy, access and experience [37], but also in creative online activity (e.g. [38]).

According to theories on political participation, socioeconomic factors play an important role in determining the likelihood of participating [27]. While online participation is said to make participation more inclusive, it engages those already interested more than those not interested yet [39] as well as those with greater privilege to be involved in e-participation than those without it [40]. These findings may be highly country specific since (political) participation is arguably constituted differently in each country/culture, as are generational and gender divides. Data on specific demographic differences in online participation are rather scarce, partly since a differentiation between forms of participation (traditional, digital or through day-to-day activities) is often not considered in evaluations (e.g. [41]).

\subsection{Gamification}

Systematic reviews and meta-analyses [19, 20, 21] report overall positive effects of gamification in terms of engagement and use. Yet, they also show that engagement through gamification relies on the context (e.g. education/learning) and on user characteristics. Several social factors have been identified to predict the perception of gamification [42]. Similarly, age and gender have been put forward to account for differences in gamification acceptance and effectiveness:

Apart from their advantage as "digital natives" [36], youth has a relatively high affinity towards games and anything game-like (own data), making them susceptible to gamification [18]. It would thus seem worthwhile to try to engage young people in public participation with game-like platforms where 
gamification could be employed as an on-boarding technique [43] A common concern is that older individuals might perceive gamification as dissuasive and would therefore be less likely to engage with a gamified platform [44], or even take (specific) game elements as a reason to stop using e-participation services [23]. Concerns pertaining to age-dependent acceptance are countered by works that found no differences in gamification acceptance (e.g. [45]). Though the acceptance and interest in gamified products differed for different age groups in [46], perceived fun and liking of gamified health with a desire to play again increased with age in [47]. Possibly due to being geared towards this target group [24], predominantly young male individuals play online [24, 48].

Yet online games are not, per se, gamification. Thus, online gaming differences are not automatically transferable to gamification settings (cf. [49, 50]. Further, differences in gamification seem to be highly context-dependent [47]. The results also point to differences due to the type of gamification employed. With studies exploring the effectiveness of gamification for specific user groups still being scarce [25], this paper aims to provide some insights by testing the effects of age in the field of gamified public participation.

\subsection{Gamified participation}

Apart from increasing participation through fun and entertainment, the rationale of linking public participation with gamefulness lies also in a game's ability to facilitate learning. For instance, in simulation games, citizens can playfully explore planning processes as well as sharing and debating ideas with other citizens. Through this collective reflection citizens may broaden their understanding of public issues and stakeholders' roles in such processes [51].

Up until now, studies have mostly focused on the general acceptance of gamification and disregarded potentially influencing factors such as demographics. As far as we are aware, the only exception is Poplin's evaluation of a web-based serious game that allows users to design their ideal marketplace [52]. The results were encouraging as both older individuals and university students indicated to be in favor of the integrated game elements (i.e. little helper, voting mechanism).

Recent findings pertaining the overall effectiveness of gamified participation are contradictory: While a field trial in Finland suggests that citizens did not care for the integrated game elements [53], a study conducted in Italy reports that adding game elements keeps citizens actively engaged and stimulates them to make their contribution more concrete by adding contextual information [54]. To explain this discrepancies it is necessary to investigate factors such as cultural context and game components used. Such insights may provide valuable insights as to who can be encouraged through gamified participation.

\section{Mobile participation field study}

In order to investigate potential influences of age and gender on different aspects of participation, we carried out a long-term field trial in Turku, Finland, where a gamified mobile participation prototype was trialled over the duration of five months. During this time, the application was free to download from the Apple App Store, Google Play Store and Windows Phone Store.

\subsection{The prototype}

The prototype was developed in an iterative process involving several user studies. With the focus on urban planning and place-based development, the concept combined a location-based participatory sourcing approach with elements from social media and games. The application allowed citizens to report issues and introduce own ideas (bottom-up), but also enabled city administration to request feedback (top-down). Contributions took the shape of geo-referenced text that could be annotated with a title, photo, point of interest, categorical tag and emoticon symbolizing an emotion the author associated with the respective issue. All contributions were visible to all users in a sortable list and on a map. Users could like and comment on individual content, encouraging further discussion. In addition to self-initiated contributions, users could also contribute to missions, which were topic-specific in-app tasks posted by a city official or citizen. Possible interactions within the application were thus: post a contribution or mission, link a contribution to a mission, create a mission, comment a contribution or comment, vote on a contribution or comment and browse content.

Integrated game elements included an achievement system (i.e. points, leaderboard) to spark competition, missions enabling the top-down scheme, time constraint (i.e. contributions have a lifetime that runs out over time) and user profiles (see Figure 1). Points are awarded for in-app activities such as commenting and creating new contributions. These points are linked to the lifetime of contributions, which is extended by activities in relation to them (e.g. voting or commenting). Profiles are essentially a summary of a user's achievements, displaying last activities, rank on the leaderboard, name and amount of points awarded. The prototype has been described in more detail in [55]. 


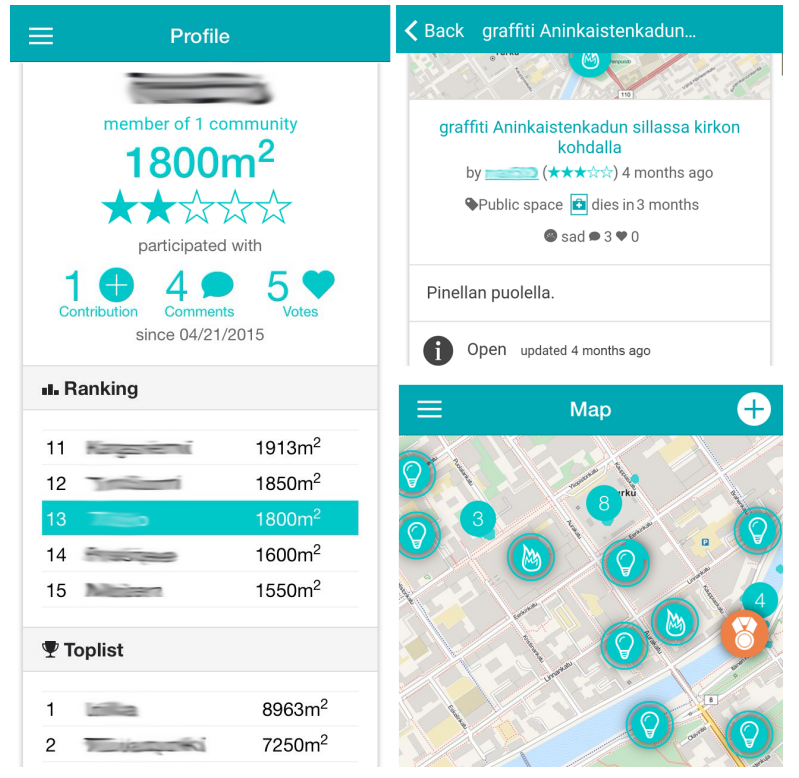

Figure 1: Screenshots of the participation prototype. Left: User-Profile with points overview and leaderboard rank. Right top: Sample contribution showing lifetime element. Right bottom: Map displaying contributions

\subsection{Data and measures}

Before and after measures consisted of two questionnaires. The first was integrated in the mobile application and automatically opened upon registering with the service. This pre-survey recorded age and gender as well as information about participants' previous involvement in politics, their experience with mobile devices and interest in urban planning. The second survey was distributed via e-mail shortly after the trial. This post-survey asked participants to report their experiences with the trial, factors encouraging usage, implications of the trial as well as other relevant aspects, such as their affinity towards games. Although both surveys were optional, the pre-survey opened itself every day until having been answered.

All survey items were assessed using Likert scales of either 5 or 10 points (1="do not agree at all", $5 / 10=$ "agree to a great extent"). Questions with a 10-point scale were taken from the European Social Survey ${ }^{1}$. The surveys were combined with back-end usage logs (i.e. usage patterns; number of contributions posted) to assess all measures relevant to this study. Due to different response rates (Pre-survey: 23\%; Post-survey: $17 \%$ ) from partially different participants (i.e. not every participant filled in both surveys),

\footnotetext{
1 www . europeansocialsurvey · org/
}

\begin{tabular}{|c|c|c|c|c|}
\hline Age & $\begin{array}{l}\text { Pre \& Post } \\
\text { survey }\end{array}$ & Pre-survey & $\begin{array}{l}\text { Activity } \\
\text { Count }\end{array}$ & $\begin{array}{l}\text { Creative } \\
\text { Content }\end{array}$ \\
\hline Under 29 & $13(26 \%)$ & $50(27 \%)$ & $8.26(8.25)$ & $1.43(1.72)$ \\
\hline $30-38$ & $12(26 \%)$ & $67(37 \%)$ & $2.0(1.09)$ & .79(.88) \\
\hline $39-51$ & $13(26 \%)$ & $39(21 \%)$ & $9.14(15.24)$ & $2.79(2.33)$ \\
\hline Over 52 & $13(26 \%)$ & $27(15 \%)$ & $3.36(2.9)$ & $.67(.82)$ \\
\hline Total & & $\overline{18} \overline{3}--$ & $\overline{4.25}(\overline{8} . \overline{14})$ & $\overline{1} . \overline{8} \overline{(5.86)}$ \\
\hline
\end{tabular}

Table 1: Overview of age groupings and sample size.

the sample size for the analyzed aspects varies: For evaluations on the effect of age and gender, we drew on all participants who responded to the pre-survey. For game affinity, motivations, perceived appropriateness of gamified application, external political efficacy, and the implications of participation, the sample contained only individuals who answered both surveys.

For the analysis of age differences in context of mobile participation, we considered the entire life-cycle of participation:

Pre-Conditions for Participation: Attitudes, subjective norms and social influence count as main determinants for behavioral intentions (theory of planned behavior TPB [56]) and technology adoption [57]. Hence, an item asked participants for their perceived internal political efficacy, i.e. whether they felt they understood politics (IPEa) and thought themselves qualified to participate in politics (IPEb; $1=$ "strongly disagree; $5=$ "strongly agree"). With mistrust being a main reason for non-participation, we aimed to investigate whether a) demographic differences in mistrust exist and b) having used a digital participation platform has changed this attitude. This was measured by participants stating their level of trust toward the local government in both the pre-survey and the post-survey ( $1=$ "no trust at all", 10= "complete trust). Another important pre-condition for engaging with mobile participation systems is having the necessary skills to use them. The pre-survey thus assessed participants' perceived mobile skills (1="beginner"; 5="expert"). To put the incorporated game elements into context, we further asked participants to indicate their game affinity (1= "not affine", 5= "very affine").

Level of participation: For comparing participation rates, we used an activity count, which refers to the sum of all communicative interactions a user undertook during the trial period (i.e. number of contributions and comments posted, amount of votes given). Participants with an activity count of zero, so-called Non-Actives, are still "participating", even though they just consume information. We further distinguish two types of participation: Merely clicking a "like"-button or signing petitions has commonly been denoted as "slactivism". A 
more active form of engagement is writing contributions and comments. As both activities lead to generated content, we operationalize the sum of those two activities as creative input.

Motivations and Barriers to Participate: Motivation is another relevant factor predicting likelihood of action and technology adoption [58]. In this study, participants were asked to indicate to what extent a list of factors influenced their motivation to use the prototype during the 5-month trial (1="not motivating", 5="very motivating"). This list included items addressing general aspects of participation (e.g. gaining feedback from city authorities), aspects specific to mobile participation (e.g. convenience of participating anytime anywhere) and those specific to gamification (e.g. earning points). In addition, we inquired whether participants thought game elements within a participatory process were appropriate (1="not appropriate at all"; 5="very appropriate").

Implications of Participation: Complementary to internal political efficacy, another relevant factor for active involvement is external political efficacy, which was by inquiring whether participants believed that their input (i.e. their contributions) had an impact on decision-making processes (1="not at all"; 5="to a great extent"). We were further interested to know whether participants had learned something new in context of their use of the mobile participation tool (1="not at all"; 5="very much") and whether participation had influenced them in any way (1="Reduced", 2="No change", 3="Increased").

\subsection{Participants}

Over the five months, 780 people registered with the participation platform, of which 183 responded to the pre-survey, 129 to the post-survey and 51 to both surveys. Respondents showed quite diverse usage patterns ranging from heavy users ("superusers") over regular users to non-active users. Participants who answered the pre-survey were well-educated and aged between 17 and 73 . With 42\% women answering the pre-survey, men as well as people aged 21-40 are slightly over-represented in this sample when compared to the general public in Turku [59]. The same holds true for the 51 participants (67\% male, $33 \%$ female) who answered both surveys.

\subsection{Groupings}

For testing our hypothesis on the perceived appropriateness of games as well as trust in official institutions, we were particularly interested in the two extremes of youngest and oldest individuals present.
Regarding the other measures such as motivations to engage, we tested all age groups to gain a holistic view.

Since several evaluations are based on the sub-sample of individuals who answered both surveys, age-groups are based on that sample of participants (see "Pre\&Post" in Table 1): To ensure similar sample sizes, we used quartiles for assigning age groups. This also automatically identified extreme groups: participants under the age of 29 are denoted as young participants $(27 \%)$ and those over 52 years as older participants $(15 \%)$. To avoid confusion, we used these age groupings for all analyses.

\section{Results}

Seeking insights about the effects of age, we conducted Spearman's rank-order correlation tests.

\subsection{Pre-conditions for Participation}

On average, all participants were at least interested in urban planning $(M=3.56, S D=.69)$. $\mathrm{A}$ weak, negative correlation between age and interest, $\mathrm{r}(183)=-.175, \mathrm{p}=.018$, contradicts common assumptions that young people are less interested in how their city is developed and general politics [60]. Likewise, political efficacy was not affected by age: Neither the perceived understanding of politics ( $r s=-.036, p=.629$ ) nor the perceived qualification to participate in politics was found to correlate ( $r s=-.020, p=.787)$ with age. The highest internal political efficacy (5p-Likert) was found for the second oldest group (39-51; $M=3.51, S D=$ $1.09)$ and the lowest for those over 52 years $(M=2.89$, $S D=1.01)$. We did not find generational differences regarding trust. Overall, all age groups are rather skeptical towards promises and claims originating from local authorities.

Supporting the generational divide theory [28], perceived mobile skills were found to negatively correlate with age $(r s=-.257, p=.000)$. Results further confirmed common propositions that young people $(M=3.33, S D=1.30)$ are more disposed to playing games than older individuals $(M=1.54, S D=.97), t(23)=3.93$, $p=.001$.

\subsection{Level of Participation}

To avoid distorting results, we excluded non-active users from this analysis (Active $n=72$; Table 1).

Activity in our mobile application was negatively correlated with age $r s(103)=-.231, \quad p=.019$. Interestingly, the group of 39-51 year olds were the most active overall and created the most creative content, followed by the youngest age group (see 


\begin{tabular}{|c|c|c|c|c|c|c|c|}
\hline & \multirow[b]{2}{*}{ Item } & \multicolumn{4}{|c|}{ Age } & \multicolumn{2}{|c|}{ Total } \\
\hline & & Under 29 & $30-38$ & $39-51$ & Over 52 & $M$ & $\mathrm{~N}$ \\
\hline & Stating one's opinion & $4.25(.97)$ & $4.67(.65)$ & $4.15(1.14)$ & $4.23(1.3)$ & $4.13(.99)$ & 123 \\
\hline & Access to information & $3.75(1.29)$ & $4.25(.45)$ & $4.15(1.14)$ & $3.69(1.18)$ & $3.71(1.06)$ & 123 \\
\hline Motivations & Receiving feedback & $3.08(1.44)$ & $3.50(.79)$ & $3.31(1.18)$ & $3.08(1.26)$ & $3.24(1.11)$ & 123 \\
\hline \multirow[t]{4}{*}{ to use } & Respond to missions & $3.17(1.03)$ & $3.33(1.30)$ & $2.85(1.07)$ & $2.69(1.11)$ & $2.86(1.18)$ & 123 \\
\hline & Game elements & $1.67(1.15)$ & $1.58(.99)$ & $1.69(.75)$ & $1.15(.38)$ & $1.63(.90)$ & 123 \\
\hline & Earning points & $2.0(1.28)$ & $1.58(.90)$ & $1.69(.85)$ & $1.23(.59)$ & $1.66(.93)$ & 123 \\
\hline & Competing for points & $1.67(.98)$ & $1.42(.90)$ & $1.38(.65)$ & $1.15(.38)$ & $1.41(.75)$ & 123 \\
\hline Trust in & Trust in local gov (pre) & $5.26(2.28)$ & $\overline{4} . \overline{8} \overline{(2.58)}$ & $6.05(2.15)$ & $\overline{5} . \overline{0} \overline{(2 . \overline{4} 0)}$ & $5.29(2.38)$ & $\overline{180}$ \\
\hline local government & Trust in local gov (post) & $5.42(2.12)$ & $5.08(1.73)$ & $5.54(2.37)$ & $5.31(2.53)$ & $5.29(2.19)$ & 122 \\
\hline Attitudes & Game affinity & $3.33(1.3)^{*}$ & $\overline{2} . \overline{8} 3(\overline{1.53)}$ & $2 . \overline{8}(1.28)$ & $1 . \overline{54}(.97)^{*}$ & $2 . \overline{7} 5(1 . \overline{4})$ & $\overline{123}$ \\
\hline towards $G P$ & Game appropriateness & $2.75(1.6) *$ & $2.75(.75)$ & $2.62(1.12)$ & $1.92(.76) *$ & $2.50(1.1)$ & 121 \\
\hline
\end{tabular}

Table 2: Summary of results for analyzed aspects. Standard deviation in parantheses. Variables highlighted in bold and marked with an asterisk indicate a significant difference.

Table 1). This underpins the assumption that there is a age-cutoff to enjoying mobile technology, which is supported by confidence in mobile technology skills depending on age. It might indicate that older individuals were to some extent left behind by this novel form of participation. Due to its similarity to social media, it could be posited that younger people are more accustomed to this form of interaction [61]. The youngest age group was most motivated by the prospect of being able to propose ideas at the beginning of the trial $(M=3.45)$. With the only significant difference found for game affinity and game appropriateness, it seems that the added gamefulness did contribute to their motivation to engage.

Apart from curiosity in a new participation method, having access to information has been the main download motivation for all age groups. Mirroring the lower values for creating content, actively discussing issues played a minor role in initial motivations to engage across all age groups.

\subsection{Demographics of Non-Actives}

Excluded from the analysis regarding level of participation, we explored demographical patterns among Non-Actives $(=$ posted no contributions, comments, did not vote) to see which individuals may be excluded by the use of novel technologies. These insights might provide valuable aspects to be considered for the design of more inclusive participation methods.

For each age group the inactivity rate was approximately $60 \%(\min 30-38: 57 \%$; $\max 39-51$ :
$63 \%)$. In terms of gender, $62 \%$ of the male participants and $57 \%$ of the female participants were Non-Actives. Thus, the likelihood to become active in a mobile gamified participation application does not seem to be affected by age or gender.

\subsection{Motivations and Barriers to participate}

We did not find any significant correlations of participants' age with gamification or participation related motivations (e.g. gaining access to information, earning points; see Table 2). This supports the previous finding that motivation and interest for public participation do not depend on age.

Least relevant for participants' motivation to engage were the game components; this particularly applies to the oldest group $(M=1.15)$. Noteworthy is further that young people seem to be more motivated by competition than older individuals. Overall, young people are significantly more likely to think that it is appropriate to gamify participation $(M=2.75)$ than their older counterparts $(M=1.92), t(23)=2.23, p=.037$.

\subsection{Implications of Participation}

The belief that officials will respond to citizens' input (= external efficacy) was not found to be affected by age. On average, both the youngest $(M=2.67$, $S D=1.25)$ and the oldest group $(M=2.69, S D=1.01)$ were similarly reluctant to believe that this form of participation can make a difference. However, the group that was most active in posting content (39-51) was the one with the lowest external political efficacy. This 
is unusual, since those who believe they can make a difference in their communities usually tend to be more active than those who do not [31]. That efficacy did not correlate with participation rate in our sample, could imply that those who do not trust officials to be responsive try to attract attention by posting even more content or that they were more invested in this specific method of trying.

Our data revealed that the impact of using a mobile participation application on levels of trust is different for age groups. While those under the age of 38 reported to trust the local government more after the trial, those over 38 stated to have lost trust (see Table 2). This decrease was significant for those between 39 and 51 years, $t(13)=-2.25, p=.044$.

Age was not found to correlate on a statistically significant level with any of the factors regarding civic learning. Participants from the two older age groups reported to have learned most on how mobile applications can be used for urban planning (39-51: $M=3,69$; over 52: $M=3,46)$. This contradicts prior findings that claim that older adults take longer to grasp the benefits of technology [62]. The youngest age group reported to have learned most about other opinions $(M=3.00, S D=1.13)$ and local issues $(M=3.50$, $S D=1.17)$. This could be interpreted in a way that while older individuals were more concentrated on technology and thus less focused on (maybe already familiar) content, younger citizens were more readily engaged with the content without focusing on the medium. All age groups stated that their belief in the usefulness of mobile applications for urban planning had increased $(M=2.68)$. Younger participants seemed to have grown slightly more optimistic $(M=2.50)$ regarding their mobile engagement having an impact compared to those over $38(M=2.27)$.

\section{Discussion}

Based on our data, we argue that young people are more attracted by digital (here mobile) participation than their older counterparts. We found that the rate of participation was affected by age but not gender. Young people (under the age of 29) were interested in discussed topics and displayed relatively high levels of active participation. It could be posited that young people believe in contemporary technology to bring about change in decision-making processes, enabling citizens to become more effectively involved. Contrary to this, the older generation lost trust after their engagement with the participation tool. This might be associated with their initial skepticism regarding novel technology.

Our findings further indicate that gamified participation is mainly a method to engage the young generation. Yet, due to the low overall participation rate and relatively low ratings of game aspects, even this group seems hesitant to make full use of them. This underlines the need to further optimize (digital) participation tools in order to meet both youth's and other age group's requirements. Our data showed that barriers for participation are not exclusively dependent on the participation method/technology, but also on citizens' attitude towards official institutions (e.g. mistrust). Attitudes are a construct of previous experience, hear-say, policies and bureaucratic infrastructure [58]. Hence, for achieving a broad and inclusive engagement it is essential for citizens to regain trust and confidence in authorities. One way to accomplish this is to prove the effectiveness of e-participation by providing regular and meaningful feedback as well as publicly considering and generating success stories by implementing citizens' suggestions.

We could not confirm the common perception that younger individuals are not interested in topics pertaining to public life [60]. In fact, young participants from this study were as interested as their older counterparts as well as the most active in using available interactive features and thus framing discussions. This might be taken as indication that digital participation tools (especially mobile ones) meet the requirements of youth and encourage them to express their opinions. Our finding, that young participants had a stronger belief in their participation making a difference, supports this conclusion. In this respect, our data contradicts previous findings, where youth was found to show a low internal political efficacy [63]. Although the assumption that older individuals perceive their digital technology skills to be lower than younger individuals was confirmed [64], relatively many citizens over the age of 52 actively engaged with our mobile application. This might partially be due to our dissemination channels. The application along with the participation process was mainly advertised through local newspapers and radio features. Both are channels that predominantly reach middle-aged and older citizens.

In general, older participants felt proficient in their mobile skills. Though not reaching the activity level of the young, the oldest age group was more diverse in their usage (i.e. more individuals used more different interactive features within the app) than those younger than 29 years. This contravenes the finding that older individuals are more focused in their technology use (e.g. use the Internet solely for specific goals and functions) [65]. Considering the high activity rates from the 39-51 year olds, it can be stated that the use of novel technologies did not entirely exclude older individuals 
from participation [44].

The lower activity, on the other hand, shows a certain reluctance to engage. [62] noted several factors that make older adults hesitant to actively participate in online communities. One explanation could be their lacking trust in officials listening or even implementing suggestions that were gathered through a mobile application. In fact, when having downloaded the app, older individuals were least motivated by the opportunity to propose own ideas and discuss local concerns - which might be explained by their skepticism pertaining to novel technologies. In that respect, participants' intentions matched their actual usage behavior across all age groups. Another reason for their hesitation might have been the added gamefulness. Our data shows that this age group is less likely to view gamified participation as appropriate than their younger counterparts. Considering that this prototype had employed a rather "light" version of gamification, this skepticism might have been stronger if we had made the game aspects more prominent.

Our findings suggest that a high internal efficacy does not guarantee (a high level of) participation. The found significant relationship between external political efficacy and rate of participation indicates that when citizens believe that their input will be heard by the city administrations and eventually have an impact, they are more likely to engage. These findings confirm the importance of assuring citizens that the gains will be greater than the costs (e.g. time) of participating [59]. Thematic factors such as the opportunity to be informed about local issues and even the convenience of in-situ participation were ranked as high motivation to participate.

\section{Limitations}

Building on self-reported data, our results might be biased by common user study phenomena (e.g. wanting to give the "correct" answer; social-desirability). As the research team did not have any contact with participants and self-reports were collected as online questionnaires, we believe to have minimized those effects. The sample size represents another limitation. Especially for the pre- and post-survey, the sample size is rather small $(n=51)$ with gender not equally distributed $(67 \%$ male, $33 \%$ female). Those parts of the study thus have to be judged cautiously. As our data does not stem from a representative sample but from users of a participation application, our results might be biased towards higher trust and efficacy.

Moreover, our findings are based on the evaluation of a very specific mobile participation prototype that makes use of a selection of game-related elements. Effects of gamification tend to differ among contexts [19]. Hence our findings might only be valid for similar systems in related contexts. Investigating whether these findings also apply to web-based participation platforms is beyond the scope of this research project. Future work will investigate the influence of specific game elements.

\section{Conclusion}

This study set out to explore the influence of age on public participation. A second focus was on the acceptance of integrated gameful aspects. We explored this through the lens of a five-month field trial in Turku (Finland) where we deployed a mobile participation application that included a selection of game elements (e.g. points, leaderboard, reputation system).

Answering questions posed in the title, a mobile gamified participation application seems to invite especially young people and leave older people skeptic about the effectiveness of the approach. While all age groups interacted, the 39-51 aged group seemed to be the most serious about their engagement. A reason for this are low levels of trust across all age groups. To build trust, participation processes need to not only be integrated in the political structures but become an essential part of them. Although the use of contemporary technology such as smartphones might attract some less engaged groups (in our study young people), it can in no way reach all. The presented results showed that due to a combination of factors (i.a. differing pre-conditions), the mobile gamified application was not able to bridge the generational gap in participation. On the other hand, this approach (mobile and gamification) did not shut older people out entirely. As a conclusion, we repeat the call to combine this approach with physical meetings, potentially particularly targeted at elderly people. Overall, we agree that participation cannot be spurred by one strategy alone, but has to take other factors into consideration [31]. Further studies should thus focus on combining different aspects (including gamification) to maximize their potential and create a more holistic approach, also investing in (more potent) methods of inviting other currently non-engaged groups.

We are ambivalent to generalize our findings outside the settings of the trial, where a mobile application with quite specific game elements was evaluated. In light of the modest motivation spurred by the employed gamification, we propose for future work to investigate whether our findings also apply to other mobile participation platforms which for instance employ a different set and implementation of game elements. 


\section{References}

[1] M. Harding, B. Knowles, N. Davies, and M. Rouncefield, "HCI, Civic Engagement \& Trust," in Proceedings of CHI'15, pp. 2833-2842, ACM, 2015.

[2] E. Vigoda, "From responsiveness to collaboration: Governance, citizens, and the next generation of public administration," Public administration review, vol. 62, no. 5, pp. 527-540, 2002.

[3] D. Stolle, M. Hooghe, and M. Micheletti, "Politics in the supermarket: Political consumerism as a form of political participation," International political science review, vol. 26, no. 3, pp. 245-269, 2005.

[4] T.-P. Ertiö, "Participatory apps for urban planning space for improvement," Planning Practice \& Research, vol. 30, no. 3, pp. 303-321, 2015 .

[5] J. Åström and Å. Grönlund, "Online consultations in local government: What works, when, and why," Connecting democracy: Online consultation and the flow of political communication, pp. 75-96, 2012.

[6] M. Bohøj, N. G. Borchorst, S. Bødker, M. Korn, and P.-O. Zander, "Public deliberation in municipal planning: supporting action and reflection with mobile technology," in Proceedings of $C \& T^{\prime} 11$, pp. 88-97, ACM, 2011.

[7] B. Wellman, A. Q. Haase, J. Witte, and K. Hampton, "Does the internet increase, decrease, or supplement social capital? social networks, participation, and community commitment," American behavioral scientist, vol. 45, no. 3, pp. 436-455, 2001.

[8] M. K. Jennings and V. Zeitner, "Internet use and civic engagement: A longitudinal analysis," Public Opinion Quarterly, vol. 67, no. 3, pp. 311-334, 2003.

[9] M. C. Gilly and V. A. Zeithaml, "The elderly consumer and adoption of technologies," Journal of consumer research, vol. 12, no. 3, pp. 353-357, 1985.

[10] S. R. McAleer, E. Panopoulou, J. Glidden, E. Tambouris, and K. Tarabanis, "Augmenting social talk: The\# ask project," in Conference for E-Democracy and Open Government, p. 61, 2016.

[11] P. A. Dutil, C. Howard, J. Langford, and J. Roy, "Rethinking government-public relationships in a digital world: Customers, clients, or citizens?," Journal of Information Technology \& Politics, vol. 4, no. 1, pp. 77-90, 2008.

[12] M. M. Conroy and J. Evans-Cowley, "E-participation in planning: an analysis of cities adopting on-line citizen participation tools," Environment and Planning $C$, vol. 24, no. 3, p. 371, 2006.

[13] J. Van Dijck and D. Nieborg, "Wikinomics and its discontents: a critical analysis of web 2.0 business manifestos," New media \& society, vol. 11, no. 5, pp. 855-874, 2009.

[14] D. Gefen and D. W. Straub, "Gender differences in the perception and use of e-mail: An extension to the technology acceptance model," MIS quarterly, pp. 389-400, 1997.

[15] H. Sun and P. Zhang, "The role of moderating factors in user technology acceptance," International journal of human-computer studies, vol. 64, no. 2, pp. 53-78, 2006.
[16] J. E. Coronado Escobar and A. R. Vasquez Urriago, "Gamification: an effective mechanism to promote civic engagement and generate trust?," in Proceedings of the 8th International Conference on Theory and Practice of Electronic Governance, pp. 514-515, ACM, 2014.

[17] S.-K. Thiel, "A Review of introducing Game Elements to e-Participation," in Proceedings of CeDEM16: Conference for E-Democracy and Open Government, pp. 3-9, IEEE, July 2016.

[18] S. Deterding, D. Dixon, R. Khaled, and L. Nacke, "From game design elements to gamefulness: defining gamification," in Proceedings of MUM'11, pp. 9-15, ACM, 2011.

[19] J. Hamari, J. Koivisto, and H. Sarsa, "Does gamification work? - a literature review of empirical studies on gamification," in Proceedings of HICCS14, pp. 3025-3034, 2014.

[20] K. Seaborn and D. I. Fels, "Gamification in theory and action: A survey," International Journal of Human Computer Studies, vol. 74, pp. 14-31, 2014.

[21] C. Silpasuwanchai, X. Ma, H. Shigemasu, and X. Ren, "Developing a comprehensive engagement framework of gamifcation for reflective learning," pp. 459-472, 2016.

[22] S.-K. Thiel and T. P. Ertiö, "Play it to Plan it? The Impact of Game Elements on Usage of an Urban Planning App," in User Centric E-Government: Challenges \& Opportunities (S. Saeed, T. Ramayah, and Z. Mahmood, eds.), p. forthcoming, Springer, 2017.

[23] A. Eveleigh, C. Jennett, S. Lynn, and A. L. Cox, "”i want to be a Captain! I want to be a Captain!": Gamification in the Old Weather Citizen Science Project," in Proceedings of the first international conference on gameful design, research, and applications, pp. 79-82, ACM, 2013.

[24] M. D. Griffiths, M. N. Davies, and D. Chappell, "Demographic factors and playing variables in online computer gaming," CyberPsychology \& Behavior, vol. 7, no. 4, pp. 479-487, 2004.

[25] B. Morschheuser, J. Hamari, and J. Koivisto, "Gamification in crowdsourcing: a review," in Proceedings of HICSS'16, pp. 4375-4384, IEEE, 2016.

[26] C. D. Kam and C. L. Palmer, "Reconsidering the effects of education on political participation," The Journal of Politics, vol. 70, no. 03, pp. 612-631, 2008.

[27] C. J. Tolbert and R. S. McNeal, "Unraveling the effects of the internet on political participation?," Political research quarterly, vol. 56, no. 2, pp. 175-185, 2003.

[28] U. Pfeil, R. Arjan, and P. Zaphiris, "Age differences in online social networking-a study of user profiles and the social capital divide among teenagers and older users in myspace," Computers in Human Behavior, vol. 25, no. 3, pp. 643-654, 2009.

[29] S. Willis and B. Tranter, "Beyond the 'digital divide' internet diffusion and inequality in australia," Journal of sociology, vol. 42, no. 1, pp. 43-59, 2006.

[30] J. McLeod, D. A. Scheufele, and P. Moy, "Community, communication, and participation: The role of mass media and interpersonal discussion in local political participation," Political communication, vol. 16, pp. 315-336, 1999.

[31] M. W. Andolina, K. Jenkins, C. Zukin, and S. Keeter, "Habits from home, lessons from school: Influences on youth civic engagement," Political Science and Politics, vol. 36, no. 02, pp. 275-280, 2003. 
[32] M. X. Delli Carpini, "Gen. com: Youth, civic engagement, and the new information environment," Political communication, vol. 17, no. 4, pp. 341-349, 2000.

[33] M. Turnšek, "'The Digital Youth Revolt?" Young People and eParticipation," Contemporary PhD eParticipation Studies in Understanding eParticipation, p. 201, 2007.

[34] S. Livingstone and M. Bober, "Interactivity and participation on the internet: Young people's response to the online invitation to engage in the civic sphere," Young citizens and new media: strategies for learning demographic engagement, pp. 395-419, 2004.

[35] D. Buckingham, "The making of citizens: Young people, news and citizenship," 2000.

[36] E. Hargittai, "Digital Na(t)ives? Variation in internet skills and uses among members of the net Generation," Sociological Inquiry, vol. 80, no. 1, pp. 92-113, 2010.

[37] S. Livingstone, M. Bober, and E. J. Helsper, "Active participation or just more information?," Information, Communication \& Society, vol. 8, no. 3, pp. 287-314, 2005.

[38] E. Hargittai and G. Walejko, "The participation divide: Content creation and sharing in the digital age1," Information, Communication \& Society, vol. 11, no. August 2012, pp. 239-256, 2008.

[39] T. Nam, "Dual effects of the internet on political activism: Reinforcing and mobilizing," Government Information Quarterly, vol. 29, no. SUPPL. 1, pp. S90-S97, 2012.

[40] D. Hutchison, T. Kanade, J. Kittler, J. M. Kleinberg, F. Mattern, J. C. Mitchell, M. Naor, O. Nierstrasz, C. Pandu Rangan, B. Steffen, and et al., "The citizens in e-participation," vol. 4084, pp. 70-82, 2006.

[41] M. A. Ackelsberg, "Broadening the study of women's participation'," Women and American Politics: New Questions, New Directions, pp. 214-236, 2003.

[42] J. Hamari and J. Koivisto, "Social motivations to use gamification: an empirical study of gamifying exercise," in Proceedings of the 21st European Conference on Information Systems SOCIAL, pp. 1-12, 2013.

[43] A. Bowser, D. Hansen, J. Preece, Y. He, C. Boston, and J. Hammock, "Gamifying citizen science: a study of two user groups," in Companion of the proceedings of CSCW'14', pp. 137-140, ACM, 2014.

[44] A. Shahri, M. Hosseini, K. Phalp, J. Taylor, and R. Ali, "Towards a code of ethics for gamification at enterprise," in IFIP Working Conference on The Practice of Enterprise Modeling, pp. 235-245, Springer, 2014.

[45] J. Cechanowicz, C. Gutwin, B. Brownell, and L. Goodfellow, "Effects of gamification on participation and data quality in a real-world market research domain," Proceedings of Gamification '13, pp. 58-65, 2013.

[46] J. V. Bittner and J. Shipper, "Motivational effects and age differences of gamification in product advertising," Journal of Consumer Marketing, vol. 31, no. 5, pp. 391-400, 2014.

[47] P. Brauner, A. Calero Valdez, U. Schroeder, and M. Ziefle, "Increase physical fitness and create health awareness through exergames and gamication. the role of individual factors, motivation and acceptance," Proceedings of the SouthCHI 2013, LNCS 7946, pp. 349-362, 2013.
[48] N. Yee, "The norrathian scrolls: a study of everquest." [Online], 2003. Available www. nickyee.com/eqt/ report.html.

[49] H. Y. Wang and Y. S. Wang, "Gender differences in the perception and acceptance of online games," British Journal of Educational Technology, vol. 39, no. 5, pp. 787-806, 2008.

[50] J. Koivisto and J. Hamari, "Demographic differences in perceived benefits from gamification," Computers in Human Behavior, vol. 35, pp. 179-188, 2014.

[51] E. Gordon and J. Baldwin-Philippi, "Playful civic learning: Enabling lateral trust and reflection in game-based public participation," International Journal of Communication, vol. 8, p. 28, 2014.

[52] A. Poplin, "Digital serious game for urban planning:"b3-design your marketplace!"," Environment and Planning B: Planning and Design, vol. 41, no. 3, pp. 493-511, 2014.

[53] S.-K. Thiel and P. Fröhlich, "Gamification as Motivation to Engage in Location-Based Public Participation?," in Progress in Location-Based Services 2016, pp. 399-421, Springer, 2016.

[54] D. Bianchini, D. Fogli, and D. Ragazzi, "Promoting citizen participation through gamification," in Proceedings of NordiCHI16, p. 8, ACM, 2016.

[55] S.-K. Thiel and U. Lehner, Exploring the Effects of Game Elements in M-participation, p. 6573. British HCI 15, ACM, 2015.

[56] I. Ajzen, From intentions to actions: A theory of planned behavior. Springer, 1985.

[57] P. Legris, J. Ingham, and P. Collerette, "Why do people use information technology? a critical review of the technology acceptance model," Information \& management, vol. 40, no. 3, pp. 191-204, 2003.

[58] B. J. Fogg, "A behavior model for persuasive design," in Proceedings of the 4th international Conference on Persuasive Technology, p. 40, ACM, 2009.

[59] J. Åström and M. Karlsson, "Will e-participation bring critical citizens back in?," in International Conference on Electronic Participation, pp. 83-93, Springer, 2016.

[60] C. Zukin, Generation $X$ and the news: news in the next century. Radio and Television News Directors Foundation, 1997.

[61] M. Duggan and J. Brenner, "The demographics of social media users, 2012," 2013.

[62] J. E. Chung, N. Park, H. Wang, J. Fulk, and M. McLaughlin, "Age differences in perceptions of online community participation among non-users: An extension of the technology acceptance model," Computers in Human Behavior, vol. 26, no. 6, pp. 1674-1684, 2010.

[63] N. A. of Secretaries of State., "New millennium project: Why young people don't vote.," 1998.

[64] R. D. Ellis and J. C. Allaire, "Modeling computer interest in older adults: The role of age, education, computer knowledge, and computer anxiety," Human Factors, vol. 41, no. 3, pp. 345-355, 1999.

[65] J. Lepa and A. Tatnall, "Using actor-network theory to understanding virtual community networks of older people using the internet," Journal of Business Systems, Governance and Ethics, vol. 1, no. 4, pp. 1-14, 2006. 